\title{
THEORETICAL STUDY AND DESIGN OF A NEW CALORIMETRIC TUNNEL
}

\author{
Jan SEDLÁČEK, Jindřich KŇOUREK, Michal KŮS
}

\begin{abstract}
An enlargement of the Pilsner R\&D park consisted of several new buildings is running nowadays. The University of West Bohemia, New technology Research centre, will be using one of the buildings also for hosting the calorimetric tunnel. With respect to our experience with currently operated calorimetric tunnel with lower power and smaller size, a new tunnel of higher power and better parameters was designed. The tunnel was proposed on the base of $1 D$ analytical calculations respecting wide range of operational regimes and possible different target applications. Together with analytical computations, also some simplified CFD simulations were done. These simulations gave us information about the flow field in the tunnel and especially in the measuring area. Some non- standardized parts of the tunnel were proposed, designed and verified with the use of CFD. The tunnel design together with its parameters and results of CFD analysis are presented in the paper.
\end{abstract}

\section{INTRODUCTION}

Calorimetric tunnel is an experimental equipment used for heat transfer measurement in technical devices, especially heat exchangers. Heat can be transported by different liquids and gases in the measured device. Air, water or water steam, glycol mixture or air-conditioning gases are mostly used. The aim of the measurement is usually determination of energy amounts transferred via heat exchanger under different operational conditions and detailed view onto fluid flow and thermal fields. With respect to wide range of heat exchangers dimensions and power characteristics, the calorimetric tunnel has to be designed properly on a heat exchanger type.

\section{CuRRently Operated Calorimetric TUNNEL}

Currently we operate a calorimetric tunnel with lower power and size - see Figure 1 . The tunnel is composed from three main circuits (for complete parameters see Table 1):

- Aerodynamic tunnel - open circuit powered by $15 \mathrm{~kW}$ axial fan with cross section approx. 0.6x0.5m,

- Liquid coolant circuit - closed loop with two pumps of different parameters, resistive water heater of power $75 \mathrm{~kW}$, controlled overpressure, mostly filled by water - glycol mixture,

- Air circuit - closed loop or open circuit powered by $7.5 \mathrm{~kW}$ radial fan, resistive air heater of power $40 \mathrm{~kW}$, controlled overpressure in case of closed loop.

\footnotetext{
- Západočeská univerzita v Plzni, NTC, Univerzitní 8, 30614 Plzeň, phone +420 377634 707, email: sedlacek@ntc.zcu.cz
}

This is an Open Access article distributed under the terms of the Creative Commons Attribution License 2.0, which permits unrestricted use, distribution, and reproduction in any medium, provided the original work is properly cited. 


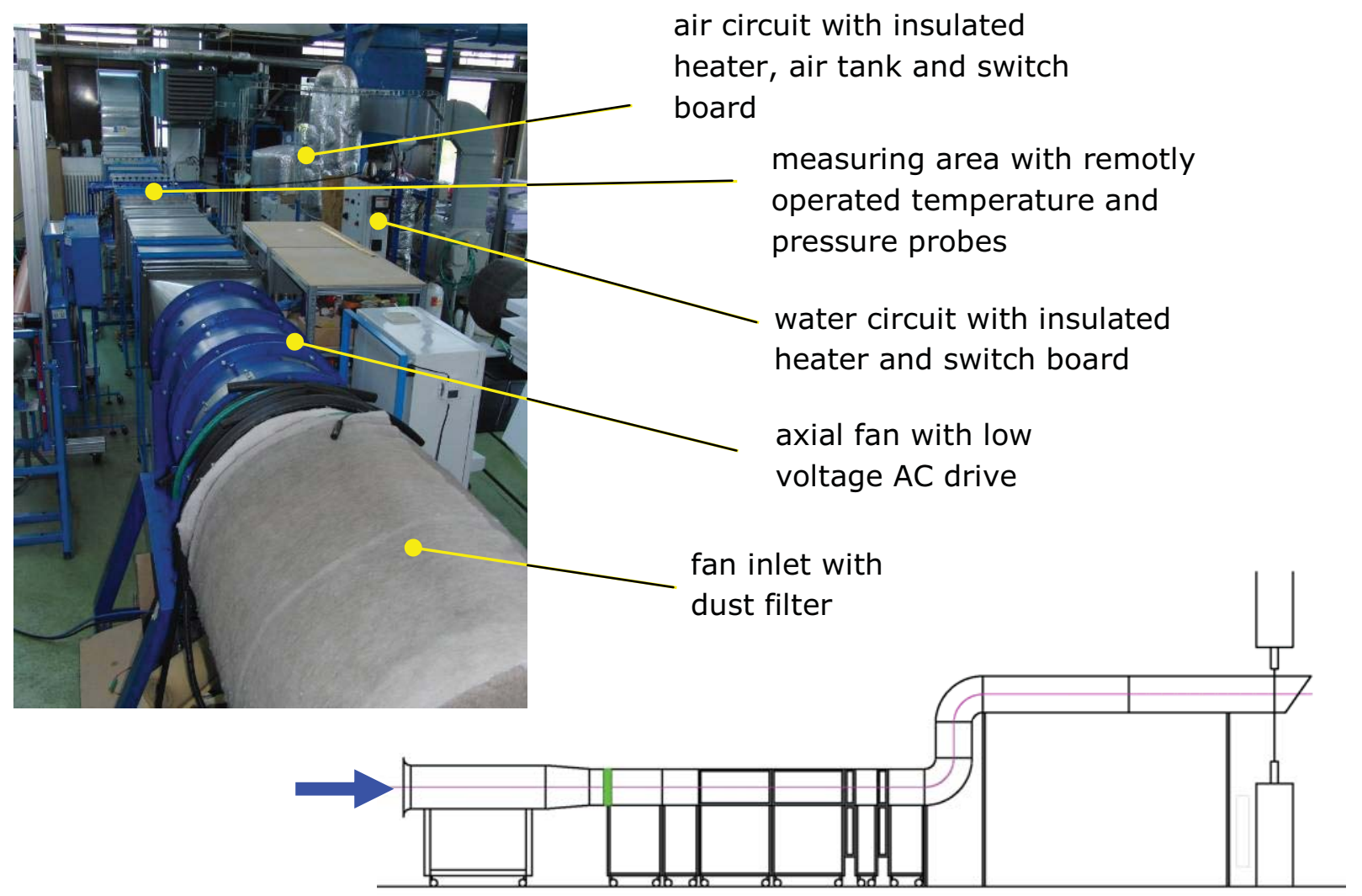

Figure 1: Photo of the currently operated calorimetric tunnel and schema of the aerodynamic tunnel

\begin{tabular}{|l|l|}
\hline \multicolumn{2}{|l|}{ Aerodynamic tunnel } \\
\hline clear area & $645 \mathrm{~mm} \times 495 \mathrm{~mm}$ \\
\hline axial fan power & $15 \mathrm{~kW}$ \\
\hline maximal overpressure & $1350 \mathrm{~Pa}$ \\
\hline maximal no-load velocity & $20 \mathrm{~m} / \mathrm{s}$ \\
\hline turbulence intensity & $3 \%$ \\
\hline Liquid coolant circuit & \multicolumn{2}{|l|}{} \\
\hline heat power & $75 \mathrm{~kW}$ \\
\hline pump 1 flow rate & $100 \mathrm{l} / \mathrm{min}$ \\
\hline pump 1 head in m & $10 \mathrm{~m}$ \\
\hline pump 2 flow rate & $35 \mathrm{l} / \mathrm{min}$ \\
\hline pump 2 head in m & $28 \mathrm{~m}$ \\
\hline maximal temperature & $110^{\circ} \mathrm{C}$ \\
\hline maximal overpressure & $2.5 \mathrm{bar}$ \\
\hline Air circuit & \\
\hline heat power & $40 \mathrm{~kW}$ \\
\hline flow rate & $180 \mathrm{~g} / \mathrm{s}$ \\
\hline temperature & $210^{\circ} \mathrm{C}$ \\
\hline overpressure & $2.5 \mathrm{bar}$ \\
\hline
\end{tabular}

Table 1:Parameters of the currently operated calorimetric tunnel 
The calorimetric tunnel is used for different experimental measurements where the aerodynamic tunnel together with the glycol mixture and / or air circuit in dependency on the measured heat exchanger are usually used. The heat exchangers: air - air; glycol mixture - air and glycol mixture - glycol mixture for automotive industry are analyzed. The analyses are focused on heat exchangers energy balance; air temperature distribution behind the exchanger and pressure loss measurement - internal and external. Sometimes there are also provided special measurement, where only one part of the calorimetric tunnel is used, e.g. analysis of an air foil profile with water injection synthetic jet.

With respect to the calorimetric tunnel parameters and characteristics, we are not able to cover all required operational points of heat exchangers in some cases. Besides of the liquid coolant and air heaters power, the measurement is limited also by: fan aerodynamic characteristics, fan motor power losses (air heating) and location of the aerodynamic tunnel / fan inflow inside the laboratory hall. The tunnel operation is therefore influenced by the air temperature inside the laboratory and also the exterior temperature.

\section{NeW CALORIMETRIC TUNNEL}

An enlargement of the Pilsner R\&D park consisted of several new buildings is running nowadays. The University of West Bohemia, New technology Research centre, will be using one of the buildings also for hosting the calorimetric tunnel. The tunnel was proposed on the base of $1 \mathrm{D}$ analytical calculations respecting wide range of operational regimes and possible different target applications [1] - see Figure 2 and 3.

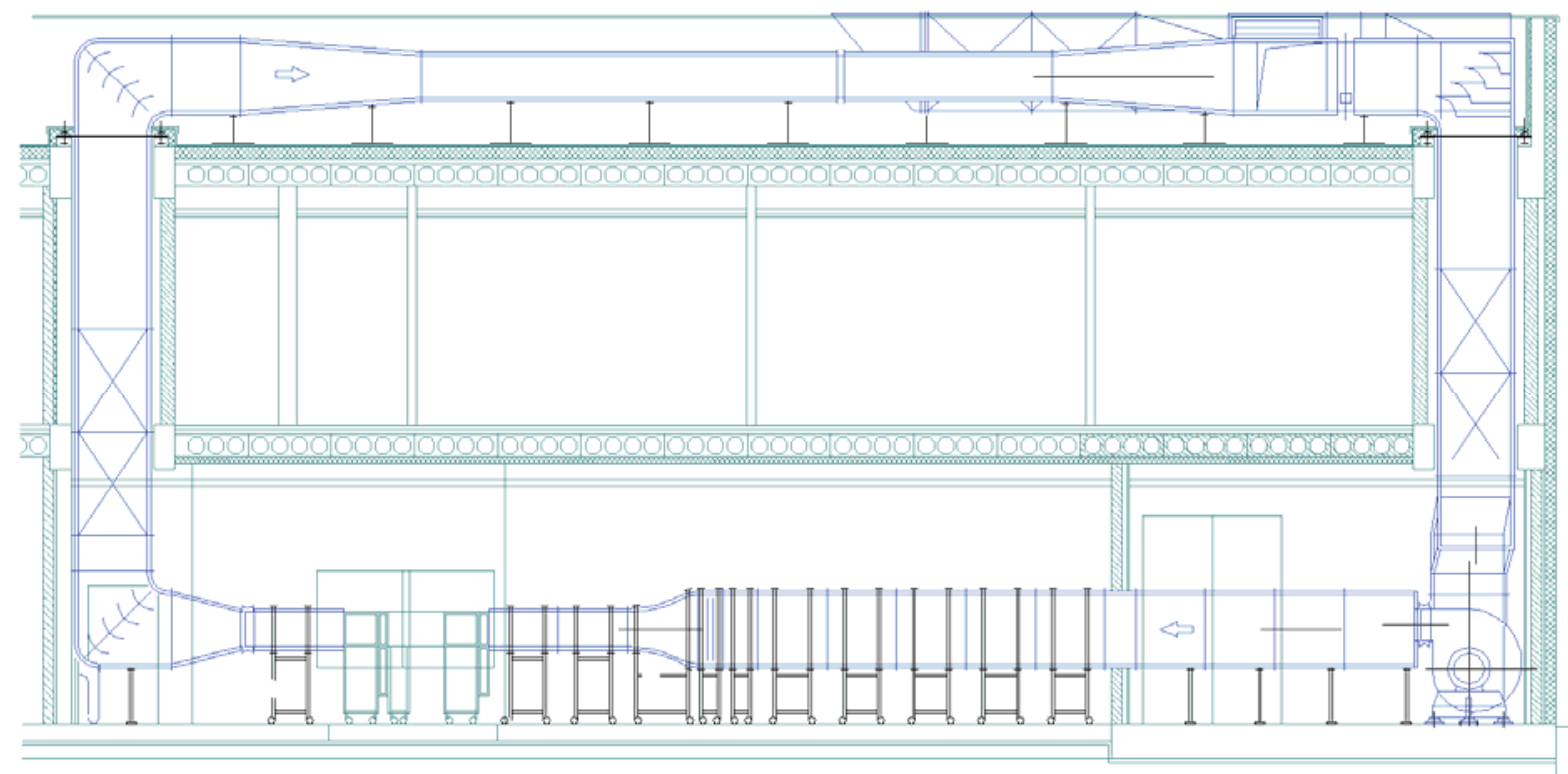

Figure 2: Schematic drawing of the new calorimetric tunnel - aerodynamic tunnel longitude section 


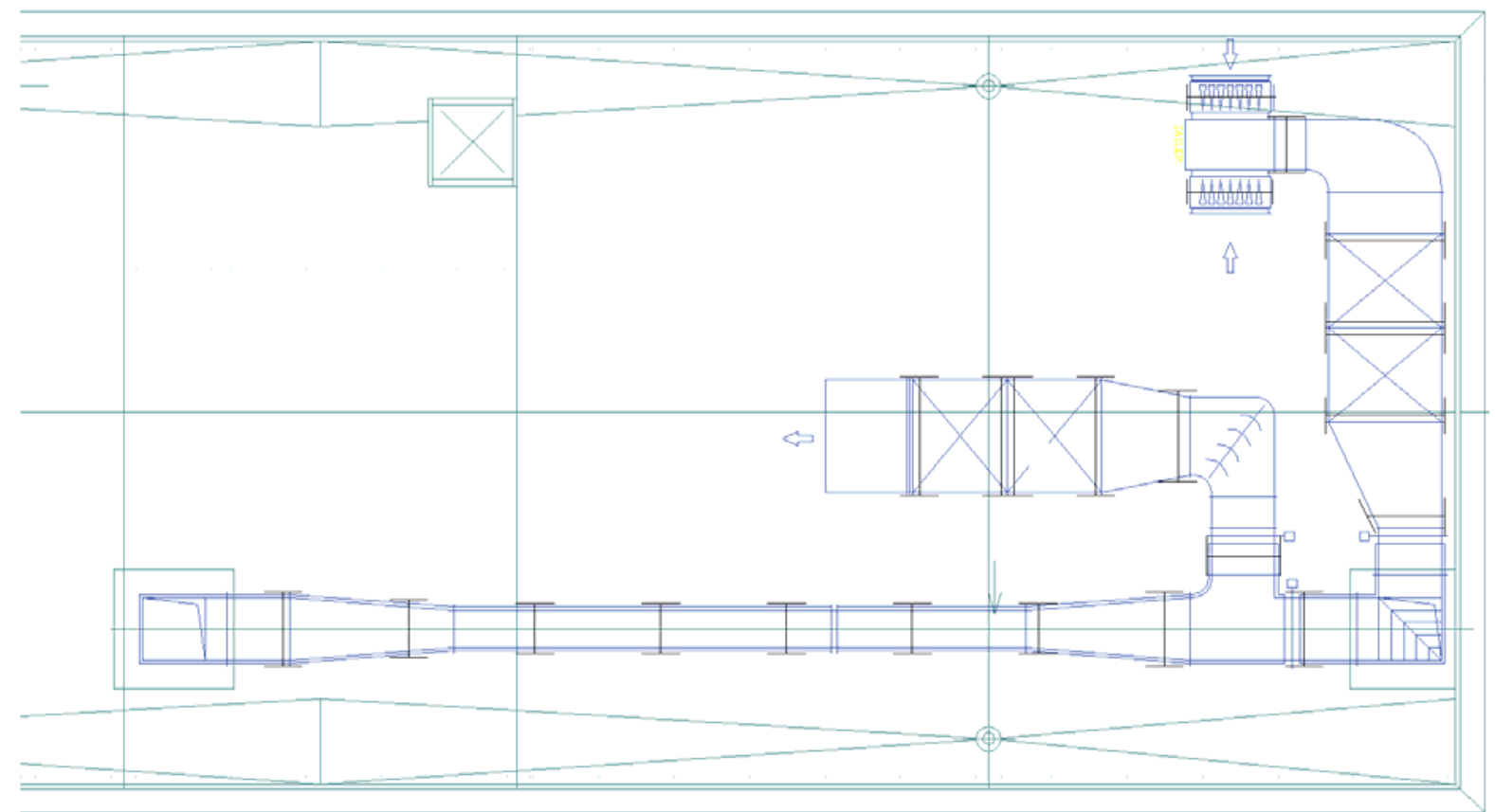

Figure 3:Schematic drawing of the new calorimetric tunnel - configuration of the aerodynamic tunnel on the building roof

The aim of the new tunnel design was to eliminate or reduce the disadvantages of the currently operated tunnel and increase its overall parameters. Regarding the opportunity to partially influence the building plan, the new tunnel was, besides of normative requirements, designed without significant restrictions.

But, the first set of required tunnel parameters was changed appreciably. The main reason was problem with finding a fan with proper characteristics. Expected wide range of mass flow rates / velocities under different pressure conditions $\left(0-20 \mathrm{~m}^{3} / \mathrm{s}\right.$ and static pressure difference up to $10 \mathrm{kPa}$ ) have been found infeasible with one type of the fan. Therefore, the required parameters were decreased. Finally, we have preselected a high pressure radial fan that covers all our requirements expected in next few years. Its main parameters can be found in Table 2. In case, the higher mass flow rates will be necessary, the fan has to be changed to another type. The motor with the drive (frequency converter) were designed with higher power - up to $200 \mathrm{~kW}$.

The selection of the fan strongly influenced the new calorimetric tunnel design. Besides of piping cross sections / pressure drops and mechanical stress, the acoustic noise and its elimination was the main factor of the tunnel design. The acoustic analysis and proposal of noise silencers together with piping construction were done by specialized company [2].

The aerodynamic tunnel was finally designed as a closed loop with inflow and outflow branches on the building roof. The rate of the circulating air and air from / to surrounding atmosphere is controlled by three shutters - in the inflow and outflow branches and between them in the main loop. The inflow branch is equipped with fabric filter and noise silencer, on the outflow branch is installed only the silencer. The noise silencers are also in both vertical branches of the main loop. The main loop piping is of cross section $1 \mathrm{~m} \mathrm{x}$ $1 \mathrm{~m}$. In the measuring area, the cross section size will be reduced in dependency on the 
measured subject needs. Smaller cross section is designed also for the direct branch of the main loop on the building roof, where the probes for measuring mass flow rate will be installed (e.g. Wilson flow grid).

Besides of the above mentioned aerodynamic tunnel, also the water and air circuits will be improved in the new calorimetric tunnel. The heaters power will be increased up to $130 \mathrm{~kW}$ resp. $80 \mathrm{~kW}$. New pump with higher parameters and better control will be also installed in the water circuit.

\begin{tabular}{|l|l|l|}
\hline & min. & max. \\
\hline rpm & 462 & 3207 \\
\hline mass flow rate $\left[\mathrm{m}^{3} / \mathrm{s}\right]$ & 0.5 & 9 \\
\hline efficiency $[\%]$ & 74 & 67.1 \\
\hline total pressure difference $[\mathrm{Pa}]$ & 365 & 10000 \\
\hline static total pressure difference $[\mathrm{Pa}]$ & 350 & 7170 \\
\hline power $[\mathrm{kW}]$ & 0.2 & 129.7 \\
\hline
\end{tabular}

Table 2:Chosen parameters of the preselected high pressure radial fan

\section{CFD ANALYSES}

Together with the analyses and design proposal described in previous chapter also some more detailed numerical analyses were done. The goal was to verify the analytical computations, check and optimize the flow profile in the measuring area and also support the design of some non conventional parts of the aerodynamic tunnel.

An example of the analyzed complete tunnel configuration is on the Figure 4, where bevel connection of the outflow branch was considered yet.

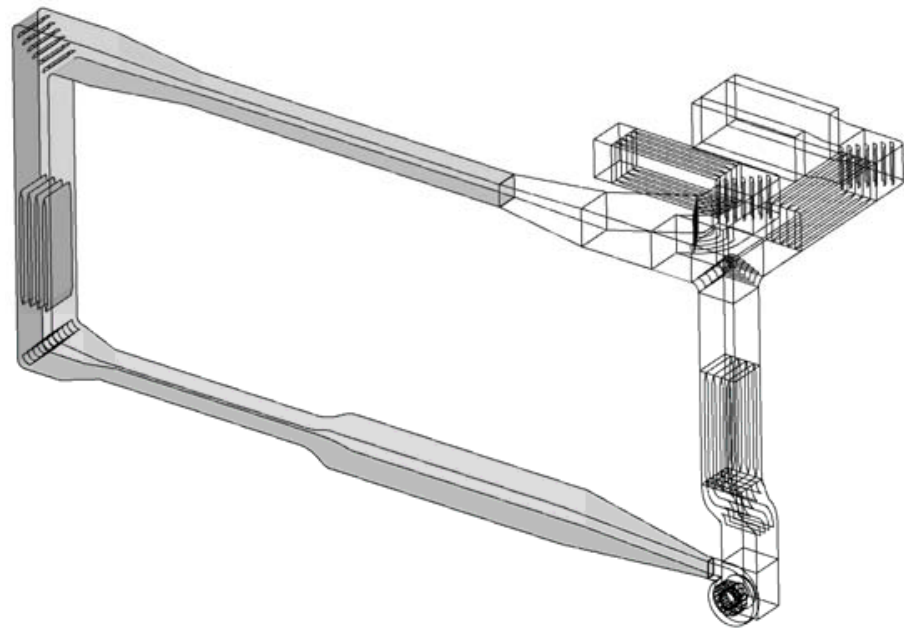

Figure 4:An example of analyzed aerodynamic tunnel configuration

To obtain the best velocity profile in the measuring area, there were analyzed different configurations of the interface: fan outlet / main loop pipeline - see Figure 5. With respect to the significant cross section difference it was considered to use a properly shaped nozzle first, but the simulations resulted into simple acute connection of the fan outlet directly into full cross section of the main pipeline. The pipeline before the measuring area is filled by mesh screens and honeycomb blocks certainly to help to equalize the velocity profile if necessary. 


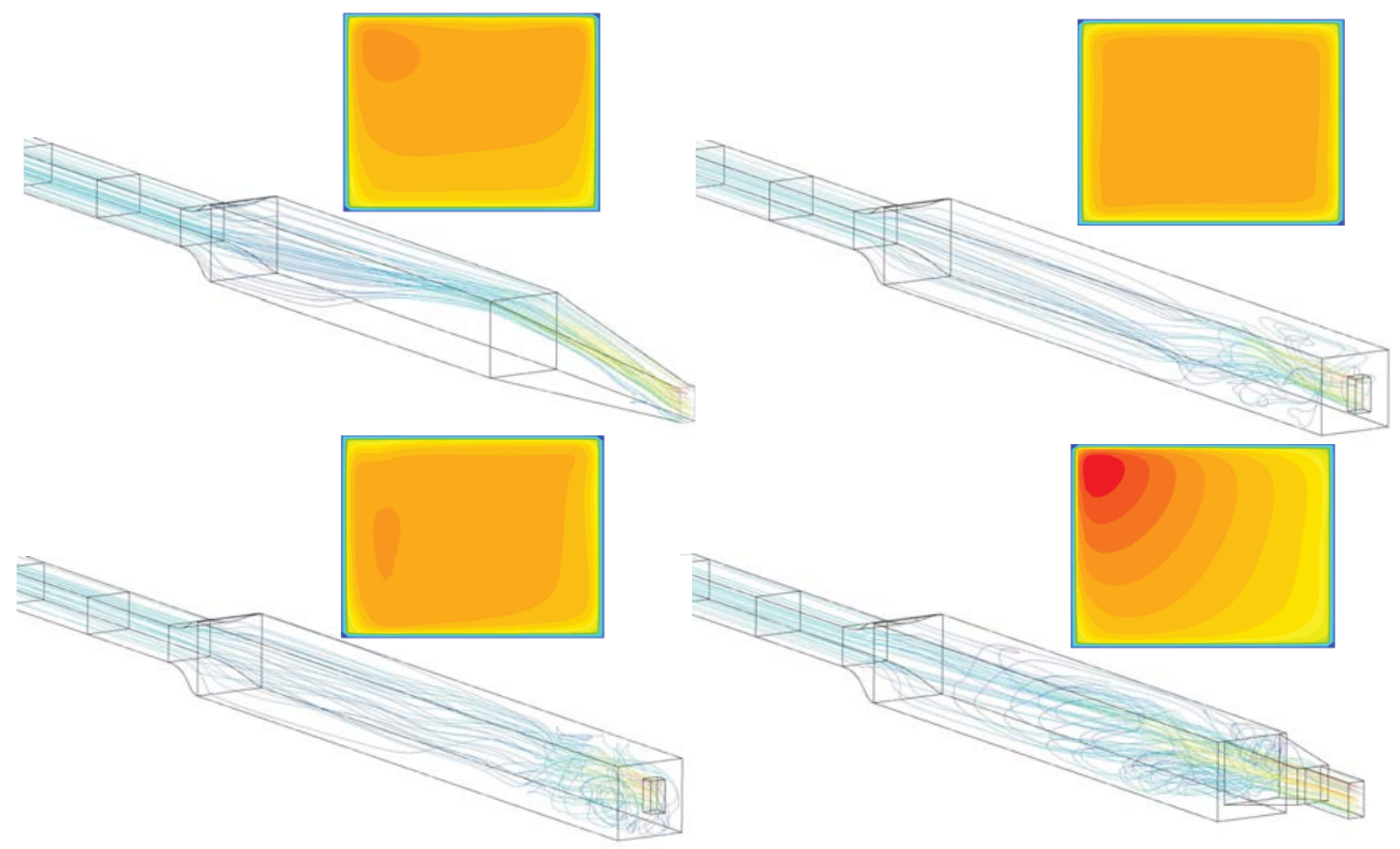

Figure 5: Different geometries of the radial fan outlet / main circuit pipeline interface - path lines colored by velocity

As a next detail of the aerodynamic tunnel design, the connections of the inflow and outflow branches to the main loop on the building roof were analyzed. Standardized and modified perpendicular and bevel junctions were tested. In the final design, the standardized $T$ junction is used for the outflow branch. On the base of CFD simulations for the inflow branch was proposed a non conventional junction with blades in two directions - see Figure 6.
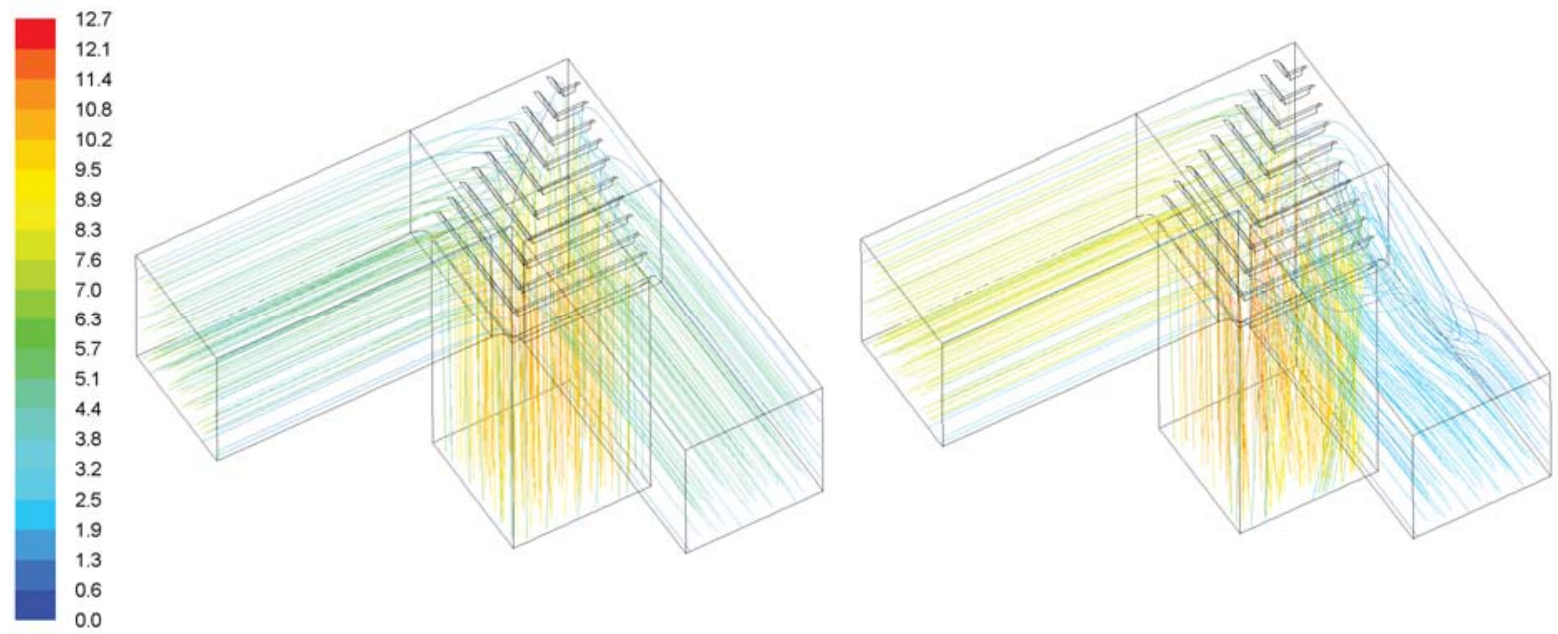

Figure 6: Path lines of the air flow in the non conventional three ways elbow with different flow rates of two inflow branches - left 0.5/0.5, right 0.8/0.2. 


\section{Conclusions}

The new buildings of the Pilsner R\&D park should be finished in the first half of the year 2012. The building works are presently underway. We have to start with detailed partial projects and finalize the calorimetric tunnel design, components and control system in few next months. We are already expecting the new tunnel with improved parameters and we hope that the tunnel confirms the presumptions and results of the project and further presented analyses.

\section{ACKNOWLEDGEMENT}

The result was developed within the CENTEM project, reg. no. CZ.1.05/2.1.00/03.0088 that is cofunded from the ERDF within the OP RDI programme of the Ministry of Education, Youth and Sports.

\section{REFERENCES}

[1] Projektová dokumentace - dokumentace pro provedení stavby. Technologická část VZDUCHOTECHNIKA. Zpracoval: KANCELÁŘ VZDUCHOTECHNIKY - Ing. M. Čížek, Písek.

[2] Akustická studie - Měřicí vzduchový tunel NTC VTP II. Zpracoval: Greif-akustika, s.r.o. Praha. 